\title{
Diagnostic implications of tear protein profiles
}

\author{
I. A. MACKIE ${ }^{1}$ AND D. V. SEAL ${ }^{2}$ \\ From the 'Department of Ophthalmology, St George's Hospital, London and the \\ ${ }^{2}$ Department of Microbiology, Northwick Park Hospital and Clinical Research Centre, Harrow, Middlesex
}

SUMmary Concentrations of lysozyme, lactoferrin, ceruloplasmin, $\operatorname{IgA}$, and $\operatorname{IgG}$ have been measured in tears by the ELISA (enzyme-linked immunosorbent assay) technique. Tears were collected on weighed filter paper discs, after which they were eluted into buffer and transported frozen to a remote laboratory for assay. Patients with sicca, questionably dry eyes and ocular pemphigoid were sampled, as were 54 normal volunteers. Tear protein profiles were established which were unique for each condition and clearly differed from the normal controls. The assay developed is considered suitable for other proteins such as IgE, and could also be used for monitoring the effects of drugs on the lacrimal gland.

We have previously described a method for assaying tear lysozyme. ${ }^{12}$ We used calibrated standards, an agar plate, and live Micrococcus luteus. We established normal values which decreased with age, and were able to detect early cases of keratoconjunctivitis sicca. We could show that the tear lysozyme concentration varied with the severity of this disease, and that fine particulate matter in the tear film was a sensitive marker of the dry eye in its early stages. We also established that the significant reading for our modified Schirmer I test was $6 \mathrm{~mm}$ or less. This agreed with Sjögren ${ }^{3}$ and von Bijsterveld ${ }^{4}$ but conflicted with Jones at $10 \mathrm{~mm}^{5}$ and Schirmer himself at $15 \mathrm{~mm} .^{6}$

We were also interested in early recognition of ocular toxicity to the beta blocker drug practolol (Eraldin), which was found to be capable of producing a dry eye together with conjunctival scarring and corneal destructive changes. ${ }^{7}$ We compared various beta blockers and showed that only practolol among them could lower tear lysozyme. ${ }^{8}$ We were also able to demonstrate low levels of lysozyme before ocular signs of toxicity were present, and we found significantly lower levels in a few patients who did not have signs of ocular toxicity. We found that we could predict the onset of toxicity in individual patients when a drop occurred in the levels of tear lysozyme.

There are many proteins in tears and we considered that there may be further diagnostic significance in alterations of these proteins in various external eye

Correspondence to Mr I. A. Mackie, FRCS, 99 Harley Street, London W1N 1DF. disease states. ${ }^{9}$ The development of a tear eluate transport system ${ }^{1}$ allowed us to turn to the ELISA method for estimating simultaneously a number of different tear proteins using tear eluates so that we could achieve a profile. This is a new application of the ELISA technique. We decided to investigate such profiles in cases of established sicca and ocular pemphigoid as well as cases in which the diagnosis of sicca was entertained but in doubt, "questionably dry eyes'.

\section{Materials and methods}

Both eyes of 7 patients with established sicca and 7 patients considered to have questionably dry eyes according to definitions previously given ${ }^{9}$ were examined and tear fluid collected on to discs. These were weighed before and after collection in a $200 \mu \mathrm{l}$ sealed plastic pot in the clinic with a Cahn automatic portable electronic balance. $150 \mu \mathrm{l}$ of phosphate buffered saline was then added to the pot to form a tear eluate, which was transported in a vacuum flask at $4^{\circ}$ to a nearby laboratory, where it was held frozen at $-20^{\circ} \mathrm{C}$ before being transported frozen in solid $\mathrm{CO}_{2}$ to a remote laboratory for the ELISA tests. Seven patients with ocular pemphigoid, 4 mild and 3 severe, were similarly examined as well as one patient with cutaneous pemphigus and clinically dry eyes. In addition 4 patients were studied with ocular rosacea and 5 with allergic conjunctivitis.

Initial development of enzyme linked immunosorbent assay for tear proteins was performed by quantifying IgG and IgA in tear eluates. ${ }^{10}$ The method 
involved direct binding of tear proteins in the eluate to plastic wells of a polystyrene plate with alkaline TRIS $0.01 \mathrm{M}$ as a coating buffer. Peroxidaseconjugated anti-IgG and anti-IgA were added after the plate was washed with PBS/tween, followed by repeated washing and OPD/hydrogen peroxide substrate. The degree of colour that developed in each well was measured with a Dynatech automatic ELISA reader. This system was later modified to use alkaline carbonate coating buffer instead of TRIS, and sealing of the plates at all stages with plastic film to give equal humidity in each well of the plate. This resulted in even binding of protein to all wells both inner and outer." With this technique assays have been developed for tear lysozyme, lactoferrin, and ceruloplasmin by means of an indirect test binding peroxidase-conjugated goat antirabbit IgG to rabbit antispecific human protein, which itself is bound to the tear protein in the plate. A direct binding test has been developed for tear IgG and IgA assay using peroxidase-conjugated specific antisera raised in rabbits. Consistent standard curves were obtained with sensitivity as low as $2 \mathrm{ng} / \mathrm{ml} .{ }^{11}$ Human lactoferrin and ceruloplasmin were obtained from Sigma Laboratories, UK, but human lysozyme came from Professor Ossermann, Columbia University, New York. Immunoglobulin preparations (IgG and IgA) were obtained from Nordic Laboratories. Problems were experienced with severe cross-reaction by some manufacturers' antisera giving considerable binding to proteins against which they were not supposed to have been raised. After this experimentation, rabbit antilysozyme, antilactoferrin, and anticeruloplasmin were purchased from Dako Laboratories, Copenhagen, which gave the most specific reactions and were of highest potency. However, goat antirabbit IgG conjugated to peroxidase was purchased from Nordic Laboratories for the final step in the indirect ELISA test. Dako's rabbit anti-IgG and antiIgA directly conjugated to peroxidase were purchased for the tear IgG and IgA assays. The levels of these 5 proteins were each measured in a single sample of tears collected separately from both eyes of 54 normal volunteers, 9 in each age group from 20 to 80 . The tears were collected on discs, similarly to those of the patients, and eluates were made during the development of these assays. ${ }^{\prime \prime}$

\section{Results}

The tear protein levels measured for each condition and normals are given in Figs. 1 to 3 , as protein concentrations in $\mathrm{mg} / \mathrm{dl}$ at each age. (SI conversion: $\mathrm{mg} / \mathrm{dl} \times 0.01=\mathrm{g} / \mathrm{l}$.) The mean normal concentration for each protein at various ages is given (solid line), as is the $95 \%$ confidence limit at twice the standard

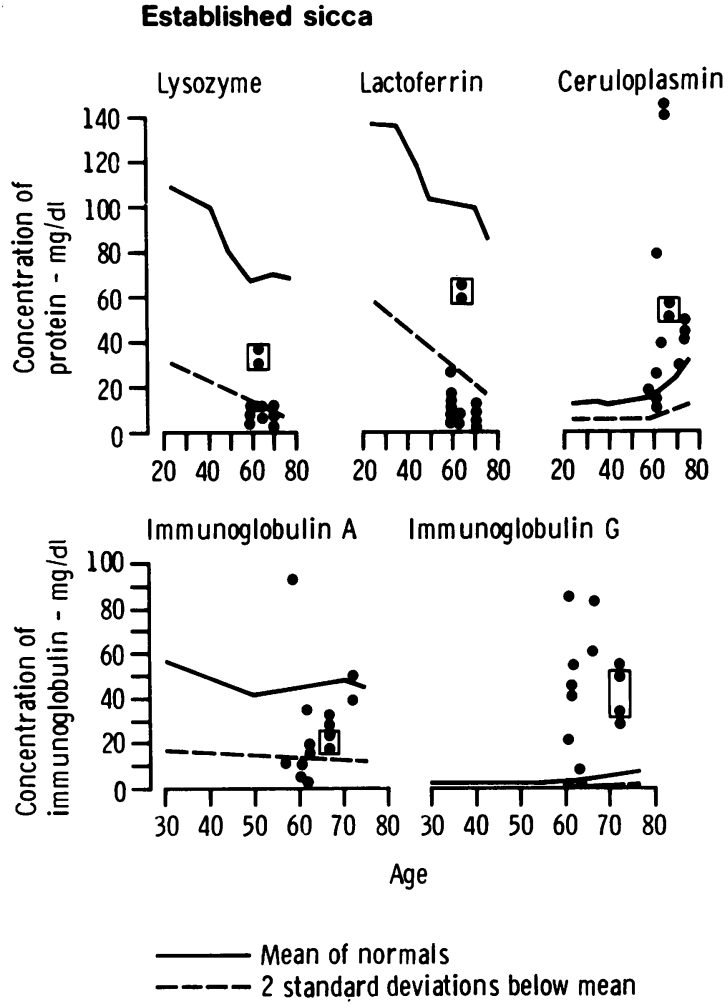

Fig. 1 Tear protein levels in sicca. (SI conversion: $m g / d l \times 0.01=g / l$.)

deviation below the mean for each age (dotted line). Lysozyme and lactoferrin decrease with age, but ceruloplasmin increases. This may be because the former are actively secreted by the acinar cells of the lacrimal gland, while the latter is produced in the liver cells and is a transudate from serum, being concentrated in conditions of reduced tear flow. IgA decreases with age while being actively secreted by plasma cells in the lacrimal gland. IgG has low to nil levels in the normal eye under age 55 , but has a small increase correlating with ceruloplasmin over the age of 60 .

\section{ESTABLISHED SICCA}

In established sicca we have found significantly decreased tear lysozyme in 6 out of 7 patients, but have also found similarly decreased levels of tear lactoferrin, which correlate with those of lysozyme. However, tear ceruloplasmin levels are greatly increased above normal owing to either a concentration effect or its secretion as a C-reactive protein from chronically inflamed vessels of the conjunctiva. Tear IgA levels are in the low to normal range or significantly decreased, while tear IgG levels are increased similarly to ceruloplasmin. 


\section{Questionably dry eyes}
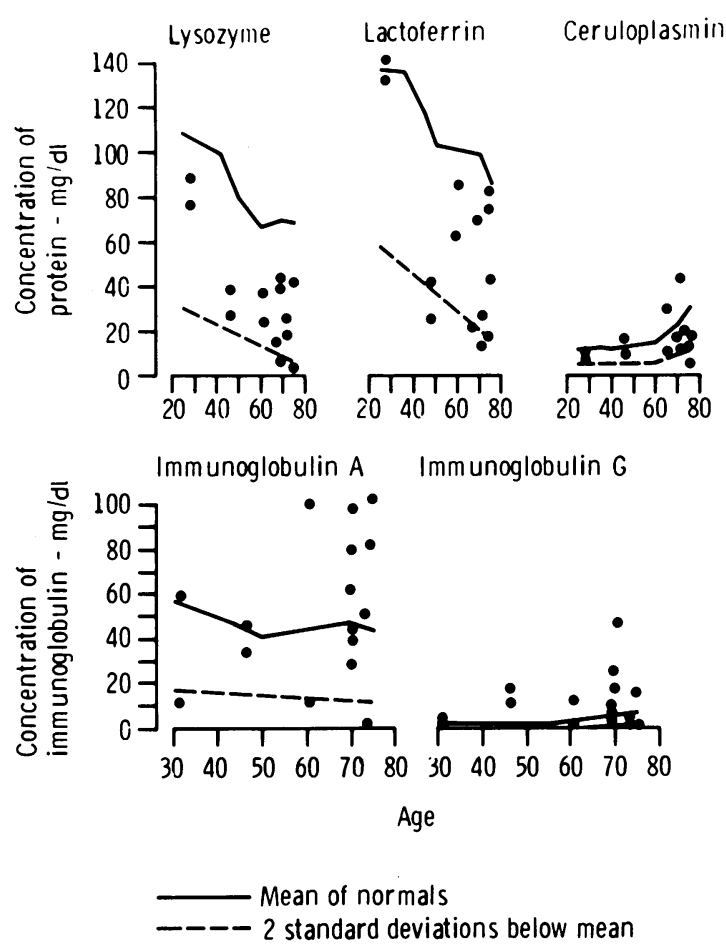

Fig. 2 Tear protein levels in questionably dry eyes. (SI conversion: $m g / d l \times 0.01=g / l$.)

\section{QUESTIONABLY DRY EYES}

With questionably dry eyes we have found similar levels of tear lysozyme as those gained in our previous study, ${ }^{9}$ which are in the low to normal range and significantly low as a group compared with a normal mean. We have also found similar low levels of lactoferrin in the same range, which correlate well with those of lysozyme. However, the tear ceruloplasmin levels were in the normal range as were the tear $\operatorname{IgA}$ levels. The levels of tear IgG were slightly raised.

\section{OCULAR PEMPHIGOID}

In patients with mild, slowly progressive ocular pemphigoid the tear lysozyme, lactoferrin, and ceruloplasmin levels were normal. The tear IgA was greatly increased in 3 eyes, while tear IgG was normal.

Three patients had severe, rapidly progressive ocular pemphigoid. In 2 patients the tear lysozyme, lactoferrin, and ceruloplasmin levels were normal, but the IgG was raised. The other patient with severe pemphigoid and concomitant dry eyes had very low lysozyme and lactoferrin levels as well as IgA, but greatly elevated ceruloplasmin and IgG levels.
Ocular pemphigoid
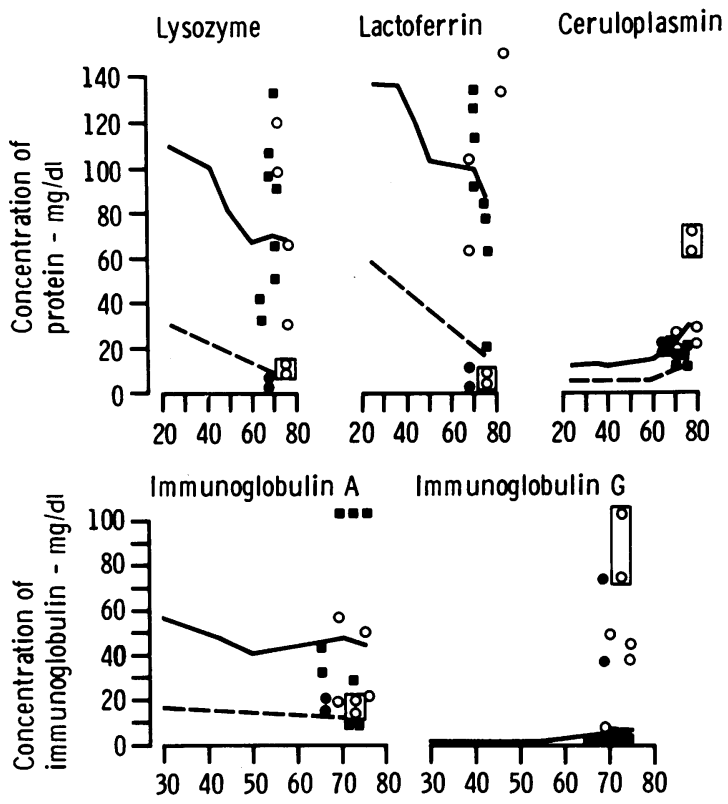

Age

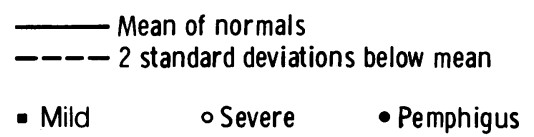

Fig. 3 Tear protein levels in ocular pemphigoid. (SI conversion: $m g / d l \times 0.01=g / l$.)

\section{PEMPHIGUS}

One patient with cutaneous pemphigus and an external eye disease problem was examined. $\mathrm{He}^{-}$had clinically dry eyes and a marked erosive keratopathy. He was found to have low lysozyme, lactoferrin, and IgA. He had greatly elevated IgG with a normal ceruloplasmin.

\section{Discussion}

The group of patients with 'questionably dry eyes' have been shown to have a definite, abnormal tear protein profile that is distinct from the normal eye and established sicca. This group can be distinguished from patients with sicca by finding low normal tear lysozyme and lacoferrin levels in the presence of normal ceruloplasmin. Sicca patients have very low tear lysozyme and lactoferrin levels with high ceruloplasmin. In questionably dry eyes there are normal tear immunoglobulin levels, whereas tear $\operatorname{IgA}$ is reduced and IgG is increased in sicca. The difference between questionably dry eyes and normals is shown 
statistically by comparing mean tear lysozyme and lactoferrin levels when a group of patients are examined. However, in the individual patient the distinction is not necessarily possible with these tests alone when results are in the low normal range, but they will serve to show that the patient does not have sicca.

It is our clinical and laboratory finding that the patients we label as having a 'questionably dry eye' often do not progress to established sicca. However, we consider that measurement of tear protein profiles gives further criteria for establishing the diagnosis of 'questionably dry'. The condition is analogous to latent diabetes, where progression is not the rule yet the patients show the same susceptibility to the complications of the disease.

Patients with ocular pemphigoid were found to have normal levels of tear lysozyme, lactoferrin, and ceruloplasmin as might indeed be expected. However, the patient with a concomitant dry eye was different and had low tear lysozyme and lactoferrin and high ceruloplasmin as we have established as typical for sicca. The high tear IgA levels with low IgG in mild ocular pemphigoid are especially interesting and suggest the possibility that they represent $\operatorname{IgA}$, rather than IgG, mediated autoimmune disease. Further studies with conjunctival biopsies might clarify the situation. In severe pemphigoid we have found the opposite, with high tear IgG levels and low IgA. It may be that the different antibodies involved reflect a different degree of 'autoimmune' pathogenicity.

The high tear IgG with normal ceruloplasmin in the patient with ocular problems associated with cutaneous pemphigus is interesting. The high $\mathrm{IgG}$ may have been an expression of his generalised autoimmune disease. It is difficult to explain the low ceruloplasmin levels in the presence of clinically very dry eyes, but the patient was severely ill and died several days after examination.

At present we have limited our profile to that of 5 proteins. We have not included our results for ocular rosacea in this paper because in the context of the 5 proteins studied they showed no significant abnormality, but a wider profile of proteins might show characteristic features in this disease. We similarly did not find alterations of the normal 5 protein profile in the patients studied with allergic disease. We are developing a method for tear IgE assay using ELISA and tear eluates, and shall be trying to assay eosino- phil major basic protein ${ }^{12}$ by this method as well. It is hoped that this will be a marker for allergic conjunctivitis, particularly when allergic disease occurs as a secondary phenomenon in another condition.

Tear protein profiles have useful potential in following up patients who are on drugs which physicians claim cause 'dry eyes'. Past experience has shown that such opinions can be misleading, ${ }^{13}$ but the previous lack of suitable tests for diagnosing the 'dry eye' was a problem. By using the tear eluate transport system it is possible to collect tear eluates in different clinics around the country and to transport them to a central remote laboratory for analysis by the ELISA technique.

We are grateful for the help of Mr J. McGill and Mr G. Liakos, Southampton Eye Hospital; Professor P. Watt, Department of Medical Microbiology, Southampton University Medical School; and Dr N. Goulding, research assistant. We also thank Professor E. F. Osserman, Department of Medicine, Columbia University, New York, for kindly donating a sample of human lysozyme to us.

\section{References}

1 Seal DV, Mackie IA, Coakes RL. Quantitative tear lysozyme assay: a new technique for transporting specimens. $\mathrm{Br} J \mathrm{Oph}$ thalmol 1980; 64: 700-4.

2 Mackie IA, Seal DV. Quantitative tear lysozyme assay in units of activity per microlitre. Br J Ophthalmol 1976; 60: 70-4.

3 Sjögren H. Zur Kenntnis der keratoconjunctivitis sicca. Acta Ophthalmol (Kbh) 1933; 11 (suppl 2): 151.

4 van Bijsterveld OP. Diagnostic tests in the sicca syndrome. Arch Ophthalmol 1969; 82: 10-4.

5 Jones LT. The lacrimal secretory system and its treatment. Am J Ophthalmol 1966; 62: 47-60.

6 Schirmer O. Studien zur Physiologie und Pathologie der Tranenabsonderung and Tranenabfuhr. Albrecht von Graefes Arch Klin Ophthalmol 1903; 56: 197-291.

7 Wright P. Untoward effects associated with practolol administration: oculomucocutaneous syndrome. $\operatorname{Br}$ Med $J$ 1975; i: 595-8.

8 Mackie IA, Seal DV, Pescod JM. Beta-adrenergic receptor blocking drugs: tear lysozyme and immunological screening for adverse reaction. Br J Ophthalmol 1977; 61: 354-9.

9 Mackie IA, Seal DV. The questionably dry eye. BrJ Ophthalmol 1981; 65: 2-9.

10 Seal DV, Mackie IA, Coakes RL, Baines CB. Timolol and lacrimal function-analysis by micro-ELISA. Res Clin Forums $1981 ; 3: 49-54$.

11 Seal DV. Pathophysiology of bacterial infection in the external eye. MD thesis, University of London, 1983.

12 Udell IJ, Gleich GJ, Allansmith MR, Ackerman SJ, Abelson AB. Eosinophil granule major basic protein and CharcotLeyden crystal protein in human tears. Am J Ophthalmol 1981; 92: 824-8.

13 Mackie IA, Seal DV. Beta-blockers, eye complaints and tear secretion. Lancet 1977; ii: 1027. 